Revista Destaques Acadêmicos, Lajeado, v. 11, n. 4, 2019. ISSN 2176-3070

DOI: http://dx.doi.org/10.22410/issn.2176-3070.v11i4a2019.2414

http://www.univates.br/revistas

\title{
REFLEXÕES SOBRE O ENSINO DE QUÍMICA E A CONFECÇÃO DE MODELOS ATÔMICOS COM MATÉRIAS REAPROVEITÁVEIS COMO PRÁTICA PEDAGÓGICA
}

\author{
Sabrina Teixeira de Sousa Silva ${ }^{1}$, Rayna Relane de Souza Teixeira ${ }^{1}$, \\ Ruth Helly Fereira Cardoso ${ }^{1}$, Rayanne Cornélio Silva Carvalho', \\ João Victor da Silva Santos', Vilma Dias de Araujo Veloso ${ }^{3}$
}

\begin{abstract}
Resumo: O Ensino de Química está presente na Educação Básica, e tem como intuito promover ao aluno a compreensão e interpretação do mundo em que vive, suas propriedades e transformações, sendo o estudo dos modelos atômicos a base para se entender a constituição da matéria. Metodologias tradicionais de ensino, em alguns casos, dificultam a compreensão do conteúdo de modelos atômicos, visto que, as vezes, se utiliza apenas o material didático e analogias, que venham a ser errôneas, além da abstração do conteúdo. A utilização de recursos pedagógicos facilita o aprendizado, e aproxima a teoria da prática, sendo uma alternativa para sanar dificuldades e aprimorar a aprendizagem. Nesse contexto, o presente trabalho tem como objetivo refletir sobre o ensino de Química, promovendo o conhecimento sobre modelos atômicos por meio da construção de modelos utilizando materiais reaproveitáveis. $\mathrm{O}$ desenvolvimento do trabalho ocorreu em uma escola pública de Ensino Médio da cidade de ParnaíbaPI, sendo os sujeitos da pesquisa alunos de uma turma de $1^{\circ}$ ano. Foram aplicados dois questionários abertos como instrumento de coleta de dados, sendo um anterior a construção dos modelos, e o outro posteriormente. Os procedimentos metodológicos necessários à realização desse trabalho foram baseados em uma abordagem qualitativa, com enfoque na Sequência de Ensino Investigativa (SEI). A análise dos dados, foi dividida em três tópicos principais, sendo estes: Perspectivas dos alunos com relação a disciplina de Química; Exposição dos modelos confeccionados em sala de aula; Contribuições da prática pedagógica proposta. Como resultado, foi possível observar que os alunos se mostraram adeptos de uma metodologia diferenciada, visto que foi notória uma melhoria no aprendizado, sendo possível uma nova visão sobre a
\end{abstract}

1 Alunas graduandas no curso de Licenciatura em Química do Instituto Federal de Educação, Ciência e Tecnologia do Piauí - Campus Parnaíba.

2 Licenciado em Química pelo Instituto Federal de Educação, Ciência e Tecnologia do Piauí Campus Parnaíba.

3 Licenciada em Pedagogia e Mestra em Educação pela Universidade Federal do Piauí - UFPI. 
utilização de diferentes práticas pedagógicas como alternativas para a construção do conhecimento e qualidade de ensino. A análise teórica foi subsidiada em trabalhos de Piaget (2005), Carvalho (2013), Silva (2013), Rufino (2014), dentre outros.

Palavras-chave: Ensino de Química; Prática Pedagógica; Modelos Atômicos; Materiais Reutilizáveis.

\section{INTRODUÇÃO}

O ensino de Química, está inserido na Educação Básica, e tem como objetivo promover ao aluno a compreensão a respeito do mundo em que vive, suas propriedades e transformações. De acordo com Andrade (2015) o ensino e a aprendizagem de conceitos científicos devem ser adaptados de acordo com a capacidade intelectual dos alunos, para que assim, se tornem conhecimentos mais interessantes. Dentre os assuntos inseridos no currículo abordado na Educação Básica, que confere o Ensino Fundamental e Ensino Médio, temos o estudo da matéria. A matéria é tudo aquilo que tem massa e ocupa lugar no espaço, sendo constituída por pequenas partículas denominadas átomos. A ideia sobre o estudo do átomo surgiu na Europa século XVII, devido o interesse dos cientistas em tentar explicar as propriedades dos gases (BROWN, LEMAY \& BURSTEN, 2005).

De acordo Atkins e Jones (2012), o primeiro argumento convincente a favor dos átomos foi apresentado, em 1807, pelo professor e químico inglês John Dalton, que propôs que o átomo era uma minúscula esfera maciça, impenetrável, indestrutível, indivisível e sem carga. Fonseca (2010) afirma que os postulados de Dalton explicavam o porquê de compostos diferentes serem formados pelos mesmos elementos químicos.

A primeira evidência experimental da estrutura interna dos átomos foi descoberta, em 1897, pelo físico Joseph John Thomson. Trabalhando com raios catódicos, Thomson concluiu que os átomos eram parte integrante de toda matéria, pois o experimento que provocava a emissão desses raios podia ser repetido com qualquer substância gasosa. $\mathrm{O}$ modelo de Thomson explicou muitas propriedades da matéria que o modelo de Dalton não era capaz de explicar, como os fenômenos radioativos e os de natureza elétrica, sugerindo que o átomo era uma esfera de carga elétrica positiva, não maciça, incrustada de elétrons, de modo que sua carga elétrica seria nula (FONSECA, 2010).

Em meados do século XX, Ernest Rutherford realizou várias experiências, as quais mostraram que o modelo de Thomson não estava correto. O modelo de Rutherford pospôs que o átomo era constituído por duas regiões, uma chamada de núcleo, que era pequeno, positivo e onde se concentrava a maior parte da massa do átomo, e outra chamada de eletrosfera, a qual era uma região com carga elétrica negativa, praticamente sem massa e que envolvia todo o núcleo. Rutherford elaborou então um modelo de átomo semelhante a um minúsculo sistema planetário, em que os elétrons se distribuíam ao redor do núcleo como planetas em torno do Sol (TEIXEIRA, 2012). 
Em 1913 o físico dinamarquês Niels Bohr, baseando-se no modelo de átomo de Rutherford, raciocinou que se os átomos só emitem radiações de certos comprimentos de onda ou de certas frequências bem determinadas, apresentam certos estados de energia bem determinados, que diferem um dos outros por quantidades de energia múltiplas de um quantum. As experiências de Bohr explicavam satisfatoriamente o modelo atômico.

Diante do que se foi contextualizado a respeito dos modelos atômicos, nota-se certa dificuldade na compreensão dos alunos, já que o assunto tratado parte de explicações análogas, cujas quais estão restritas, muitas das vezes, a gravuras presentes no material didático. Ao partir de analogias o aluno "[...] cria uma imagem e o átomo deixa de ser um modelo para ser real, palpável e similar à imagem que a analogia criou, fazendo com que a ideia principal do modelo matemático que deu origem a esse modelo atômico seja distorcida" (MELO \& NETO,2013, p.115).

Visando a importância de compreender a evolução dos modelos atômicos, desfazendo-se de analogias errôneas, faz-se necessário a utilização de recursos pedagógicos para melhorar seu entendimento e sua forma real. A utilização de recursos pode contribuir com a efetivação da compreensão do que se é abordado em sala de aula, sendo que "o envolvimento dos estudantes nas atividades que utilizam modelos didáticos e ilustrações promove uma melhor assimilação dos conteúdos e aquisição do conhecimento" (CORPE \& MOTA, 2014, p. 2071).

Partindo deste pressuposto, pode-se propor a construção de modelos atômicos pelos alunos, utilizando-se como matéria-prima materiais que seriam descartados. Devido à grande quantidade de lixo, reaproveitar se torna uma atitude cada vez mais importante para a manutenção da saúde do planeta e das pessoas. Reduzir a quantidade de lixo é um compromisso importante e permanente. $\mathrm{O}$ uso de materiais reaproveitáveis para produção de novos que venham a servir como recursos didáticos, promove, além do conhecimento técnico, uma conscientização sobre o meio ambiente (FONSECA, 2010).

Nesse contexto, o presente trabalho objetiva refletir sobre o ensino de Química, promovendo o conhecimento sobre modelos atômicos por meio da construção de modelos utilizando materiais reaproveitáveis. Com isso, especifica-se reconhecer a importância, a evolução histórica e os diferentes tipos de modelos atômicos, e a partir desses conhecimentos elaborar modelos didáticos através do aproveitamento de materiais que seriam descartados, enfatizando assim o aprendizado e reflexões sobre o Ensino de Química.

\section{CONTEXTO E METODOLOGIA DE PESQUISA}

A pesquisa sobre a construção de modelos atômicos utilizando materiais reaproveitáveis foi realizada em uma escola de Ensino Médio da rede pública da cidade de Parnaíba-PI, sendo proposta com o intuito de apresentar aos alunos 
um recurso para o Ensino de Química com o enfoque no conteúdo de modelos atômicos. Os procedimentos metodológicos necessários para a realização desse trabalho basearam-se em uma abordagem qualitativa, objetivando compreender o aprendizado dos alunos a partir da prática, fugindo da realidade do cotidiano escolar.

A escolha da abordagem qualitativa se justifica, pois esta é uma metodologia emergente em vez de pré-definida. De acordo com Gerhardt e Silveira (2009, p.32) “a pesquisa qualitativa preocupa-se, portanto, com aspectos da realidade que não podem ser quantificados, centrando-se na compreensão e explicação da dinâmica das relações sociais".

Partindo da pesquisa qualitativa, tem-se como metodologia especifica a Sequência de Ensino Investigativa (SEI), uma vez que os sujeitos do trabalho pesquisaram e apresentaram um resultado. Carvalho (2013) afirma que, a SEI parte da elaboração de uma problemática elaborada pelo professor, o que dá início ao processo de ensino-aprendizagem, servindo, em alguns casos, para sistematizar ou analisar a aprendizagem dos alunos. Segundo a autora as atividades investigativas por meio da SEI, seguem as seguintes etapas: proposição de problema e distribuição do material pelo professor; resolução do problema por grupos de alunos; sistematização dos conhecimentos adquiridos; comunicação do conhecimento.

A coleta de dados foi realizada em dois momentos, fazendo o uso de questionários abertos como instrumento. Tais questionários têm como vantagem, segundo Nogueira (2002), a característica de explorar todas as possíveis respostas a respeito de um questionamento. Sendo assim, permite ao pesquisado responder livremente usando sua linguagem própria e expressando opinião sobre o que está sendo abordado.

Os sujeitos da pesquisa foram discentes de uma turma de $1^{\circ}$ ano do Ensino Médio, sendo a atividade realizada com aproximadamente quarenta alunos. Primeiramente realizou-se a apresentação dos integrantes da pesquisa, onde posteriormente foi entregue um primeiro questionário, que tinha como intuito analisar as concepções dos alunos com relação a disciplina de Química. Em um segundo momento, os integrantes da pesquisa, com o consentimento do professor titular da turma, ministraram uma aula referente aos modelos atômicos, apresentando seus idealizadores e características, sendo esses os modelos de Dalton, Thomson, Rutherford e Bohr, para que assim os alunos pudessem ter um conhecimento prévio referente ao trabalho realizado, bem como revisar o conteúdo que foi abordado pelo professor.

Posteriormente a exposição da aula, os alunos foram divididos em quatro grupos, para que logo em seguida fosse realizado um sorteio que definiria qual modelo atômico seria construído por cada um. Ao definir os grupos e seus respectivos temas, foi apresentado à turma os materiais reaproveitáveis que poderiam ser utilizados para a realização do trabalho, sendo estes: garrafas PET, arames, jornais, revistas em desuso etc. 
No terceiro encontro com a turma, os grupos com seus respectivos temas e materiais reaproveitáveis colocaram em prática a modelagem de seus átomos. Durante a realização dos modelos atômicos de Dalton e Thomson (Figura 1A e 1B), os alunos utilizaram revistas e jornais em desuso, o mesmo aconteceu para os modelos de Rutherford e Bohr (Figura 1C e 1D), sendo que além de jornais e revistas, utilizaram também garrafas PET, massa de modelar e arames, com a finalidade de ilustrar os orbitais atômicos que estes modelos apresentam em sua constituição. A partir disso, foi possível criar uma conscientização a respeito da reutilização de materiais descartáveis, bem como envolver os alunos no conteúdo por meio da atividade proposta. Ao decorrer da atividade surgiram muitas dúvidas por parte dos alunos, pois eles queriam realizar os modelos com a maior fidelidade possível seguindo o que é descrito pelo livro didático, com isso ocorreu a aprendizagem do tema de forma mais eficaz e satisfatória.

Figura 1 - Modelos didáticos elaborados pelos alunos utilizando materiais recicláveis, representando o modelo atômico de Dalton (A), Thomson (B), Rutherford (C) e Bohr (D).

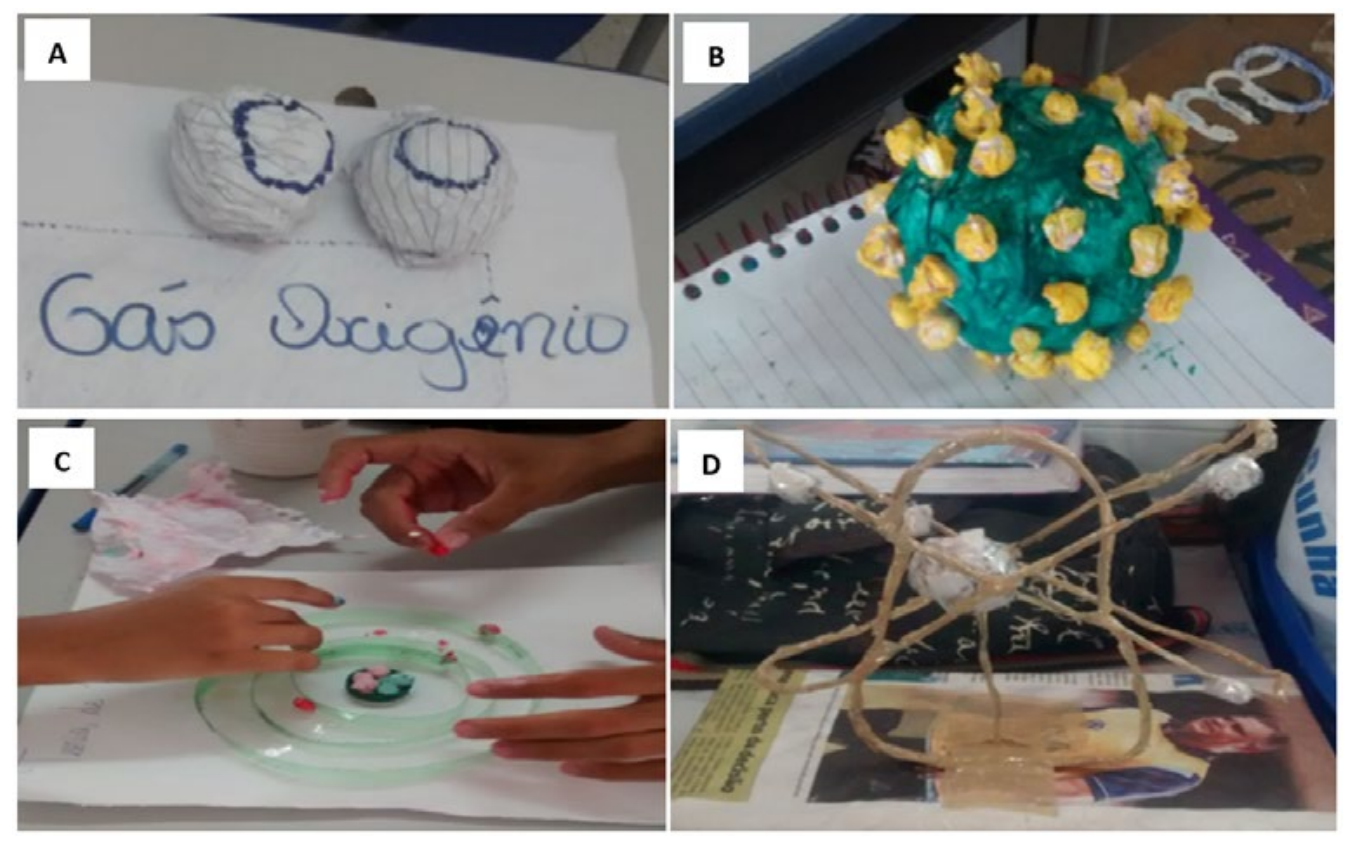

Fonte: Autoria própria, (2019).

Por fim, no quarto encontro, os grupos apresentaram em forma de seminários seus modelos para a turma, explanando as características propostas por seus idealizadores. Partindo da apresentação, gerou-se uma forma integral de aprendizagem da turma diante de todos os modelos propostos pelo trabalho. Ao fim das apresentações o segundo questionário foi entregue, tendo como 
finalidade comparar o aprendizado e as contribuições da atividade proposta, finalizando assim a realização do trabalho.

A análise dos dados obtidos por meio dos questionários constituiuse em uma análise documental qualitativa. Nascimento (2009) afirma que a investigação no entorno da Análise Documental tem estabelecido como objetivo, simultaneamente, o conteúdo e descrição analítica do documento, favorecendo a identificação de conceitos. Com o intuito de preservar a identidade dos pesquisados, os sujeitos foram identificados pela inicial " $A$ " e um numeral.

\section{RESULTADOS E DISCUSSÃO}

A apresentação dos dados deu-se por meio da análise dos questionários e pela observação dos pesquisadores diante da confecção e da apresentação dos modelos pelos alunos, com isso dividiu-se em três tópicos principais: Perspectivas dos alunos com relação a disciplina de Química; Exposição dos modelos confeccionados em sala de aula; Contribuições da prática pedagógica proposta.

\section{Perspectivas dos alunos com relação a disciplina de Química}

Tal tópico parte da análise do primeiro questionário, que teve como objetivo averiguar as perspectivas dos alunos em relação a disciplina de Química, sendo dividido, de acordo com o que se foi questionado, nas seguintes categorias: Interesse pelas aulas de Química; Dificuldades de aprendizagem; Sugestões para a promoção de aulas mais atrativas; Compreensão do conteúdo ao decorrer da aula.

\section{Interesse pelas aulas de Química}

O processo de ensino-aprendizagem é feito pelo professor e aluno, onde o professor será o mediador do conhecimento, e o aluno, por meio deste, irá construir seus valores. É de suma importância que o professor não seja apenas um orador ou que domine todos os conceitos de sua área, pois a aprendizagem não é somente o repasse de conteúdo, é necessário fazer com que o ensino se efetive de forma significativa para o aluno. Quando questionado se o professor facilitava o processo de aprendizagem, A6 (2019) afirma que:

Não, pois não há diálogo entre o aluno e o professor (A6, 2019).

Quando não há interação entre professor e alunos, podem surgir certas dificuldades que geram desmotivação. Através do diálogo é possível perceber as dificuldades que os alunos apresentam, além de permitir uma troca de experiências e de conhecimento. Neste sentido, o diálogo oportuniza a construção da relação entre professores e alunos, proporcionando participação e o processo educativo (PIAGET, 2005). 
Quando questionados se gostavam das aulas de Química, alguns dos alunos afirmaram que sim, apontando a disciplina como interessante, mas que é necessária uma sala especializada para que possa entender melhor o conteúdo.

Eu gosto sim de todas as aulas de Química, para mim é muito bom e interessante aprender sobre a matéria, átomos tudo que é explanado pela Química, quando o assunto está ficando um pouco complicado aí então chega a hora de testar mais conhecimento e mais esforço por isso que gosto (A1, 2019).

Sim. Acho uma matéria bem agradável, interessante, mas eu encontro muitas dificuldades. Para entender melhor deveria ter uma sala especializada para poder fazer algumas práticas (A12, 2019).

O interesse pelas aulas de Química está ligado a compreensão do mundo que nos rodeia, a curiosidade em entender fenômenos da natureza ou até mesmo em conhecer as substâncias presentes no dia a dia. Cardoso e Colinvaux (2000) destacam que os alunos acham interessante o estudo da Química, devido a presença desta matéria em suas vidas, permitindo um melhor conhecimento do mundo.

A ausência de laboratórios de Química nas escolas torna a compreensão de alguns fenômenos e de alguns conceitos difíceis, visto que a experimentação é uma atividade que atrai o aluno e ainda oportuniza uma melhor interação entre teoria e prática. Como afirma Ferreira e Freitas (2016), os experimentos promovem a compreensão da natureza da ciência e dos conceitos científicos, além de auxiliar no desenvolvimento do caráter científico e na análise de percepções não científicas.

Segundo Silva (2013), o ensino de Química ainda segue de maneira tradicional, na qual gera o desinteresse pela disciplina, por mais que ela esteja ligada ao nosso cotidiano. Adequar as metodologias de ensino buscando abordar o assunto de outras maneiras, a fim de promover a aprendizagem, é uma forma de minimizar o desinteresse dos alunos e suprir a falta de recursos presentes nas escolas, tornando as aulas mais atrativas.

\section{Dificuldades de aprendizagem}

Quando indagados sobre quais as dificuldades relacionadas a aprendizagem de Química, alguns dos alunos apontam os cálculos e as reações químicas como maior obstáculo, como destacado nas respostas abaixo:

As minhas dificuldades são só quando eu faço uma leitura de um determinado assunto e não compreendo muito no começo, é só eu ler mais de uma vez e então dar tudo certo, uma dificuldade maior é quando entra em alguns cálculos (A1, 2019). 
Aprender as reações químicas (A4, 2019).

De acordo com Paz et al. (2008), a metodologia utilizada pelo professor é um motivo marcante na dificuldade do aprendizado de Química, na qual tem um maior foco na memorização das fórmulas, priorizando os cálculos e desvalorizando à experimentação e a aprendizagem. No que diz respeito as reações químicas, Araújo et al. (2012) destaca que os alunos têm uma percepção equivocada, sendo esse problema relacionado com a forma de ensino e a apresentação que os livros didáticos trazem. Geralmente essa percepção equivocada está relacionada ao fato de que algumas abordagens utilizadas tendem a ser tradicionais e abstratas, assim dificultando a relação do tema estudado com a realidade.

\section{Sugestões para a promoção de aulas mais atrativas}

Quando questionamos sobre uma forma mais atrativa de aprender Química, os alunos apontaram diversas maneiras que facilitariam sua aprendizagem, como por exemplo, a utilização de tecnologias, práticas em laboratório, experimentos, imagens, metodologias diferenciadas etc. Abaixo segue algumas das respostas:

Para ficar mais atrativo seria muito bom que fossem usados outros métodos para não ficar só naquela mesma coisa, tais como demonstração de imagens, vídeos, o professor fazendo assim ficaria bem mais atrativo $(\mathrm{A} 1,2019)$.

Seria mais atrativo se tivesse um laboratório para fazer as experiências, e assim tornaria mais fácil aprender (A2, 2019).

Com mais dinâmicas, mais aulas diferentes do normal e que seja engraçado, não cansativa como está sendo $(A 6,2019)$.

Bom seria com materiais de Química, com explicações melhores, com algumas práticas de outros modos, para que possa entender o assunto $(\mathrm{A} 9,2019)$.

Através das respostas obtidas é possível perceber que a metodologia utilizada pelo professor torna a aula cansativa e desinteressante, onde os alunos sentem a necessidade de outras abordagens para que possa de fato aprender Química. Diversas metodologias podem ser empregadas em sala de aula, combatendo assim o insucesso do aprendizado e a desmotivação. A utilização de recursos didáticos preenche lacunas que o ensino tradicional geralmente 
deixa, expondo o conteúdo de forma diferenciada e fazendo com que os alunos sejam participantes da aprendizagem (CASTOLDI \& POLINARSKI, 2009).

A experimentação no processo de ensino-aprendizagem tem sua importância justificada quando se considera sua função pedagógica de auxiliar o aluno na compreensão de fenômenos e conceitos químicos. Segundo Plicas et al. (2010), a necessidade dos alunos de relacionar os fenômenos sobre os quais se referem os conceitos justifica a experimentação como parte do contexto escolar, minimizando a ruptura entre a teoria e a prática.

Muitas escolas ainda não possuem laboratórios, ou não dispõem de alguns recursos tecnológicos, contudo o professor pode buscar outras formas para uma metodologia diferenciada. $\mathrm{O}$ ensino através de modelos didáticos e jogos possibilita a visualização de estruturas que ficam apenas no imaginário do aluno, ou que se restringem apenas na visualização do livro didático, além de promover uma melhor compreensão dos temas, permiti uma maior dinâmica na sala de aula. Dessa forma, a utilização de diversas práticas pedagógicas contribui para a construção do conhecimento, dinamizando as aulas e despertando o interesse do aluno em aprender e buscar conhecimento.

\section{Compreensão do conteúdo ao decorrer da aula}

Ao serem indagados se compreendiam o conteúdo quando o professor está ministrando a aula, muitos alunos apontaram ter dificuldades em acompanhar o que está sendo exposto, como sugere algumas das respostas obtidas:

Não. Por causa dos alunos barulhentos, e a falta de ânimo do professor com a matéria $(\mathrm{A} 8,2019)$

As vezes, pois, a sala fica fazendo muito barulho e a conversa atrapalha $(\mathrm{A} 2,2019)$

Não na hora, só com o tempo (A5, 2019)

A indisciplina pode ser causada por diversos fatores, e que por muitas vezes, além de atrapalhar o andamento da aula, atrapalha também a aprendizagem e o foco de alguns alunos. Segundo Boarini (2013), a falta de motivação é apontada como uma das causas da indisciplina escolar. Para que os alunos se desenvolvam de forma desejável, é importante que o professor supra suas necessidades, desta forma, Sprenger (2008), destaca que para ocorrer esse desenvolvimento é necessário que os professores estejam cientes dos desafios enfrentados. Pezzini e Szymanski (2015) ressaltam que quando a aula não é muito interessante, geralmente os alunos não conseguem se sentir estimulados, com isso podem tumultuá-la, assim como quando percebem a insegurança 
do professor. Os autores ainda destacam que quando ocorrem esses fatos, é necessário que o docente reveja seus métodos e planejamento.

\section{Exposição dos modelos confeccionados em sala de aula}

Após a construção dos modelos atômicos com os materiais reutilizáveis disponibilizados, os alunos prepararam e apresentaram um seminário, seguindo a ordem da evolução dos modelos atômicos estudados. De acordo com Veiga (2008), o seminário é uma metodologia que promove a socialização, uma vez que os alunos formam grupos objetivando estudar, investigar e discutir temas, sendo orientados pelo professor.

Na aula de apresentação do seminário, o primeiro grupo expôs o modelo atômico de Dalton, ressaltando a importância de se estudar a matéria e o átomo, além de explicar a teoria atômica com auxílio do modelo confeccionado, que foi representado por uma bola de revistas amassadas e coladas, demonstrando-o como uma bola maciça e indivisível, assim como apresentado no livro didático.

O segundo grupo apresentou o modelo atômico de Thomson, explicando o porquê do modelo de Dalton ser equivocado e introduzindo uma nova teoria proposta, onde o átomo possuiria subpartículas positivas e negativas, sendo não indivisível. Tal modelo foi representado por uma bola grande feita de jornais e revistas coladas, onde seria a camada positiva do átomo e as bolas menores seriam as partículas negativas encrustadas na camada positiva, fazendo relação com o modelo do pudim de passas. Os participantes apontaram as características no modelo produzido com os materiais disponibilizados, explicando suas propriedades a partir do que podia ser visualizado.

O terceiro grupo apresentou o modelo atômico de Rutherford, onde através de experimentos, apontou as falhas do modelo de Thomson, surgindo assim a necessidade da elaboração de uma nova teoria sobre a constituição do átomo. As características do modelo atômico foram apresentadas e relacionadas com o modelo produzido pelos alunos, que utilizaram bolinhas de jornais e revistas para representar os prótons e elétrons. A eletrosfera ao redor do núcleo foi representada por arames, similar ao modelo do sistema planetário. Por fim, o modelo atômico de Bohr foi apresentado pelo quarto grupo, onde destacaram primeiramente a importância do aprimoramento da teoria de Rutherford, e explicaram sobre o comportamento do átomo e suas subpartículas, demonstrando no modelo confeccionado, onde as bolinhas de jornais e revistas representavam os prótons, nêutrons, elétrons, e os anéis (obtidos da garrafa PET) representavam as camadas de energia, como mostra o modelo do sistema solar.

Durante as apresentações, foi notório que os alunos estavam envolvidos no trabalho proposto, uma vez que confeccionaram estruturas atômicas e as apresentaram com eficácia, além de ressaltarem a importância da utilização de 
materiais em desuso, reconhecendo assim a conscientização sobre a reutilização dos materiais que seriam descartados.

O uso de abordagens que partem da SEI, como afirma Silva (2017), tem se mostrado uma opção que pode ser adotada por professores, a fim promover a motivação dos alunos, melhorando o processo de ensino-aprendizagem. Ao propor aos alunos uma problemática, que seria a confecção dos modelos e sua apresentação, com o intuito de minimizar analogias errôneas, pode-se estimular a aprendizagem, além de instigar a argumentação por meio dos seminários apresentados.

\section{Contribuições da prática pedagógica proposta}

O presente tópico parte da análise do segundo questionário, que objetiva averiguar as concepções dos alunos quanto ao que se foi proposto, sendo dividido, de acordo com os questionamentos levantados, nas seguinte categorias: Concepção dos alunos quanto a confecção dos modelos atômicos; Auxílio dos modelos didáticos na aprendizagem de conteúdo; Perspectivas quanto as aulas teóricas e práticas.

\section{Concepção dos alunos quanto a confecção dos modelos atômicos}

Logo após a confecção dos modelos atômicos, foi aplicado o segundo questionário. Ao serem indagados sobre a proposta da confecção dos modelos, os alunos responderam que:

Eu achei que foi muito bom a ideia de fazer o modelo atômico (A5, 2019)

Achei muito legal, bem produtivo (A8, 2019).

Achei muito legal trabalhar com a confecção do modelo atômico, ajudou a entender melhor o assunto (A10, 2019).

Corpe e Mota (2014) destacam que a inclusão de estudantes em atividades utilizando modelos didáticos e ilustrações possibilitam uma melhor assimilação dos conteúdos e aquisição do conhecimento, sendo a utilização de recursos visuais essencial no que diz respeito à motivação e entusiasmo, conferindo aos professores, alternativas para o ensino. De acordo com Rufino (2014), o ensino através do lúdico apresenta dois elementos característicos: o prazer e o esforço espontâneo, podendo ser considerado como prazeroso pela capacidade de imergir o aluno de forma tão intensa na atividade que cria o clima de entusiasmo. A autora ainda ressalta que a idade seja respeitada, sendo a atividade lúdica proposta de acordo com o aprendiz. 


\section{Auxílio dos modelos didáticos na aprendizagem de conteúdo}

Quando questionados se a construção dos modelos ajudou no processo de aprendizado, os pesquisados responderam que foi possível uma melhor compreensão do assunto, por meio dos detalhes que a construção dos modelos proporcionou, como sugerido pelas seguintes respostas:

Sim. Para mim ajudou muito para uma compreensão melhor do modelo atômico, foi muito bom esse modelo atômico e eu aprendi muito mais (A1, 2019).

Sim, porque foi bem explicado para ser relacionado com os outros assuntos $(\mathrm{A} 5,2019)$

Sim, pois ao fazer o modelo atômico compreendi melhor o assunto $(\mathrm{A} 7,2019)$.

Ajudou sim, porque explicou de forma detalhada o assunto (A10, 2019).

Ajudou sim, porque dá para ver melhor como ele funciona (A11, 2019).

Sim, por que ajudou para que eu entendesse melhor o assunto (A13, 2019).

Os alunos destacaram que a confecção dos modelos ajudou na compreensão do conteúdo abordado, e que a explicação ficou mais clara sendo possível relacionar com outros conteúdos. Segundo Cavalcante e Silva (2008), os modelos didáticos possibilitam a experimentação, onde se tem a oportunidade de correlacionar a teoria e a prática, propiciando assim a compreensão de conceitos e o desenvolvimento de habilidades. Para Corpe e Mota (2014), os modelos didáticos são importantes ferramentas de trabalho no qual o professor, precisa proporcionar possibilidades para a construção do conhecimento, oferecendo oportunidade para o diálogo de saberes, a socialização e o desenvolvimento pessoal, social e cognitivo.

\section{Perspectivas quanto as aulas teóricas e práticas}

Quando questionados sobre as aulas teóricas e práticas, os alunos demonstraram compreender a importância de ambos métodos de ensino, onde apontaram a teoria como importante e base para a aula prática. Abaixo algumas das respostas obtidas: 
Para mim são necessárias as duas aulas tanto a teórica e a prática, necessita-se mais de práticas para que os professores façam mais essas aulas, e teorias também é muito importante (A1, 2019).

É um conjunto dos dois, pois sem explicação não dá para entender e com a aula prática ficou melhor de conhecer o assunto (A2, 2019).

As duas maneiras, eu acho que a teórica é a base de tudo (A3, 2019).

[...] de acordo com meu entendimento as duas são bem eficazes e necessárias (A12, 2019).

Segundo Filho (2007) a aula teórica é adequada quando se pretende abordar conceitos, definições e mecanismos de ações, tendo como vantagem sobre as demais técnicas, a velocidade de transmissão de informação. No que refere a participação dos alunos, as aulas teóricas são limitadas. De acordo com Souza et al. (2015), as aulas práticas possibilitam que o aluno saia da postura de expectador para ser um participante ativo nas etapas de seu processo de aprendizagem. Ainda destacam que as aulas não necessitam ser apenas em laboratórios, e que a prática é indissociável da teoria, visto que a teoria surge da prática. O professor necessita ter o equilíbrio entre a abordagem prática e teórica, possibilitando o enriquecimento de suas aulas e facilitando o aprendizado dos alunos.

\section{CONSIDERAÇÕES FINAIS}

Diante do que se foi abordado ao decorrer do trabalho foi possível levantar reflexões sobre o Ensino de Química. Por meio da confecção de modelos atômicos utilizando materiais reaproveitáveis como prática pedagógica, partindo da SEI, foi possível perceber ferramenta metodológica é de grande relevância para o processo de ensino-aprendizagem de Química. De acordo com as respostas do primeiro questionário, sugere-se que os alunos estavam desmotivados com os assuntos da disciplina por diversos fatores, entre eles, a relação professor-aluno e a abstração que a matéria possui principalmente.

A construção dos modelos proporcionou uma ótima interação entre o conteúdo já estudado em sala de aula e os modelos confeccionados pelos próprios alunos, de modo que puderam ter uma visão bem mais significativa e ampla do assunto em questão quando a construção dos modelos. Atividades que relacionam teoria e prática são uma ferramenta eficaz no âmbito escolar, visto que proporcionam o crescimento intelectual e a fixação do conteúdo por meio do conhecimento adquirido, e é notório que os alunos participantes desenvolveram suas habilidades, e demonstraram uma melhor sintonia entre todos através do trabalho em equipe. 
Desta forma foi possível concluir a importância da aplicação de metodologias diferenciadas que envolvam os alunos desenvolvendo sua criatividade, de modo a aprofundar os conhecimentos de Química expostos em sala de aula, aprimorando a prática pedagógica. É pertinente a dificuldade de aprendizagem no Ensino de Química, principalmente por ser uma disciplina muito rejeitada pelos alunos, devido seu grau de complexidade, porém quando unida à uma metodologia eficaz proporciona uma melhor relação professoraluno e um processo de ensino-aprendizagem mais eficaz.

\section{REFERÊNCIAS}

ANDRADE, J. S. A abordagem de modelos atômicos para alunos do $9^{\circ}$ ano do ensino fundamental pelo uso de modelos e modelagem numa perspectiva histórica. Dissertação (Mestrado Profissionalizante em Ensino de Ciências), Universidade de Brasília, Distrito Federal. 2015. 156f.

ARAUJO, F. T. S et al. Concepções dos alunos do Ensino Médio sobre reações Química. In: $2^{\circ}$ Congresso Químico do Brasil, 2012, Natal-RN. Anais do II Congresso Químico do Brasil, 2012.

ATKINS, P. W.; JONES, L. Princípios de Química: questionando a vida moderna e o meio ambiente. 5. ed. Porto Alegre: Bookman, 2012.

BOARINI, M. L. Indisciplina escolar: uma construção coletiva. Psicologia Escolar e Educacional, v. 17, n. 1, 2013.

BROWN, T.; LEMAY, H. E.; BURSTEN, B. E. Química: a ciência central. 9 ed. PrenticeHall, 2005.

CARDOSO, S. P.; COLINVAUX, D. Explorando a motivação para estudar Química. Química Nova, v. 23, n. 3, p. 401-404, 2000.

CARVALHO, A. M. P. O ensino de Ciências e a proposição de sequências de ensino investigativas. In: CARVALHO, A. M. P. (Org.). Ensino de Ciências por investigação: condições para implementação em sala de aula. São Paulo: Cengage Learning, 2013.

CASTOLDI, R.; POLINARSKI, C. A. A. Utilização de Recursos Didático-Pedagógicos na Motivação da Aprendizagem. In. I Simpósio Nacional de Ensino de Ciência e Tecnologia. 2009.

CAVALCANTE, D.; SILVA, A. Modelos didáticos e professores: concepções de ensino-aprendizagem e experimentações. In: XIV Encontro Nacional de Ensino de Química, Curitiba, UFRP, 2008.

CORPE, F. P.; MOTA, E. F. Utilização de modelos didáticos no ensino-aprendizado em imunologia. SBEnBio. $n^{\circ}$ 7, p. 2070-2080, 2014. 
FERREIRA, R. M. ; FREITAS, A. S. A função metodológica do laboratório de Química no processo de ensino e aprendizagem para o Ensino Médio em duas escolas da rede pública estadual em São Luis-MA. 2016. Disponível em: $<$ http:/ / www. eneq2016.ufsc.br/anais/resumos/R0336-1.pdf:> . Acesso em: dezembro de 2019.

FILHO, A. P. Aula teórica: quando utilizar?. Medicina (Ribeirao Preto. Online), v. 40, n. 1, p. 3-6, 2007.

FONSECA, M. R. M. Completamente Química, Ciências, Tecnologia \& Sociedade. São Paulo: Editora FTD S.A., 2010.

GERHARDT, T. E.; SILVEIRA, D. T. (Org.). Métodos de Pesquisa. Universidade Aberta do Brasil - UAB/UFRGS e pelo Curso de Graduação Tecnológica Planejamento e Gestão para o Desenvolvimento Rural da SEAD/UFRGS. - Porto Alegre: Editora da UFRGS, 2009.

MELO, M. R.; NETO, E. G. Dificuldades de Ensino e Aprendizagem dos Modelos Atômicos. Química Nova, v. 35, n. 2, p. 112-122, 2013.

NASCIMENTO, L. M. B. do. Análise documental e análise diplomática: perspectivas de interlocução de procedimentos. São Paulo, Marília, Tese (Pós-Graduação em Ciência da Informação). Universidade Estadual Paulista Faculdade de Filosofia e Ciências. 2009. p.198.

NOGUEIRA, Roberto. Elaboração e análise de questionários: uma revisão da literatura básica e a aplicação dos conceitos a um caso. Rio de Janeiro: UFRJ/ COPPEAD, 2002. 26 p.

PAZ, G. L et al. Dificuldades no ensino-aprendizagem de Química no Ensino Médio em algumas escolas públicas da região sudeste de Teresina. Anais PIBIC, UESPI, 2008 .

PEZZINI, C. C.; SZYMANSKI, M. L. S. Falta de desejo de aprender, Causas e Consequências. 2015. Disponível em:< http:/ / www.diaadiaeducacao.pr.gov.br/ portals/pde/arquivos/853-2.pdf:>. Acesso em: dezembro de 2019.

PIAGET, J. Seis estudos de psicologia. 24. ed. Rio de Janeiro: Forense Universitária, 2005.

PLICAS, L. M. A. et al. O uso de práticas experimentais em Química como contribuição na formação continuada de professores de Química. Instituto de Biociências, letras e Ciências Exatas - UNESP, São José do Rio Preto, 2010.

RUFINO, T. C.S. O lúdico na sala de aula - em séries iniciais do ensino fundamental. Trabalho de Conclusão de Curso (Especialização em Fundamentos da Educação: Práticas Pedagógicas Interdisciplinares) - Universidade Estadual da Paraíba, Guarabira, 2014. 
SILVA, S. G. As Principais Dificuldades na Aprendizagem de Química na Visão dos Alunos do Ensino Médio. In: IX Congresso de Iniciação Científica do IFRN. 2013.

SOUZA, A. P. A. et al. A Necessidade da Relação Entre Teoria e Prática no Ensino de Ciências Naturais. Revista de Ensino, Educação e Ciências Humanas, v. 15, 2015.

SPRENGER, M. Memória: como ensinar para o aluno lembrar. Porto Alegre: Artmed, 2008.

SILVA, E. G. Sequência de Ensino Investigativa: a evolução dos modelos atômicos. Produto Educacional (Mestrado) - IFG - Campus Jataí, Programa de Pós-Graduação em Educação para Ciências e Matemática. 2017.

TEIXEIRA, M. C. S. Novo método de aprendizagem. Vol. Único. São Paulo: DCL, 2012.

VEIGA, I. P. A. O seminário como técnica de ensino socializado. In: VEIGA, I. P. A. (Org). Técnicas de ensino: por que não?. 19ª ed. Campinas: Papirus, 2008. 